\title{
Pengukuran Arus dan Frekuensi pada Alat Elektrostimulator
}

\author{
Caesar Febri Nugroho \#, Endro Yulianto, Sumber, Abdul Kholiq \\ Departemen Teknik Elektromedik Poltekkes Kemenkes, Surabaya \\ Jl. Pucang Jajar Timur No. 10, Surabaya, 60245, Indonesia \\ \#caesar.soekotjo@gmail.com, endro_yulianto.com, sumberrani@gmail.com, \\ kawulloh@gmail.com
}

\begin{tabular}{l}
\multicolumn{1}{c}{ Info Artikel } \\
\hline Penerimaan Artikel: \\
Diterima 9 Maret 2019 \\
Revisi 15 Des 2020 \\
Terbit 18 Des 2020
\end{tabular}

Kata kunci:

Alat Ukur

Sensor ACS 712

Arus dan Frekuensi

\begin{abstract}
Abstrak
Pengukuran merupakan kegiatan membandingkan suatu besaran yang diukur dengan alat ukur yang digunakan sebagai satuan. Alat ukur tens ini digunakan untuk mengukur tingkat frekuensi keluaran, arus keluaran dan menampilkan bentuk sinyal pada suatu alat tens yang mempunyai standart tertentu untuk bisa digunakan. Tujuan dari penelitian ini adalah mendesain sebuah alat pengukuran arus dan frekuensi pada TENS yang memiliki nilai standart tertentu agar dapat digunakan untuk melakukan terapi kejut listrik yang memiliki tingkat frkuensi rendah ataupun frekuensi tinggi agar keluaran sesuai dengan standart yang digunakan. Keuntungan dari penelitian ini adalah sistem pengukuran frekuensi dan arus dapat langsung dilakukan tanpa memerlukan instalasi kelistrikan agar dapat segera melakukan pengukuran, karena alat yang dibuat penelitian ini bersifat portable atau tidak memerlukan instalasi listrik 220v. Penelitian ini menggunakan sensor arus berjenis ACS712 untuk mendeteksi arus keluaran dari alat TENS. Komponen yang digunakan pada penelitian ini antara seperti mikrokontroler ATmega328 sebagai pusat kendali dari pemberian perintah pada alat agar dapat bekerja, LCD TFT Nextion 3,2 inch sebagai sebagai penampilan arus dan frekuensi keluaran TENS dalam bentuk angkan serta penampilan bentuk sinyal dan modul charger sebagai pengisian baterai ketika baterai habis. Penelitian ini merupakan eksperimen murni dan belum ada peneliti yang membuat alat ini sebelumnya. Untuk penelitian lebih lanjut dapat menambahkan parameter lain dan mengembangkan bentuk sinyal menjadi 2 bentuk sinyal, menambahkan indikator tegangan sebagai indikator pengaman dan penambahan indikator daya baterai agar mengetahui presentase baterai yang tersisa.
\end{abstract}

\begin{abstract}
Measurement is an activity comparing a quantity that is measured by a measuring instrument used as a unit. Tens measuring instrument is used to measure the level of output frequency, output current and display the shape of the signal on a tens tool that has a certain standard to be used. The purpose of this study is to design a current and frequency measurement tool on TENS that has a certain standard value so that it can be used to conduct electric shock therapy that has a low frequency or high frequency level so that the output matches the standard used. The advantage of this research is that the frequency and current measurement system can be directly carried out without the need for electrical installation so that it can immediately take measurements, because the instrument made in this study is portable or does not require 220v electrical installations. This research uses ACS712 type current sensor to detect the output current from the TENS tool. The components used in this study include the ATmega328 microcontroller as the control center of giving commands to the device to work, the Nextion 3.2-inch TFT LCD as a display of current and frequency output of TENS in the form of a wave and the appearance of a signal and charger module as charging the battery when the battery runs out. This research is a pure experiment and no researchers have made this tool before. For further research, it can add other parameters and develop the signal form into 2 signal forms, add a voltage indicator as a safety indicator and add a battery power indicator to determine the percentage of remaining battery.
\end{abstract}

\author{
Penulis korespondensi: \\ Endro Yulianto \\ Departemen Electromedical Teknik \\ Poltekkes Kemenkes, Surabaya \\ J1. Pucang Jajar Timur No. 10, Surabaya, 60245, Indonesia \\ Email: endro76@gmail.com
}

\section{Pendahuluan}

Sindrom piriformis adalah neuritis cabang saraf sciatic yang disebabkan oleh tekanan otot piriformis yang terluka atau teriritasi. Insiden dari sindrom piriformis hingga sekarang belum jelas, namun diduga sekitar $6 \%$ sampai $36 \%$ kasus ini menjadi penyebab dari low back pain dan sciatica. Fisioterapi
This work is an open access article and licensed under a Creative Commons Attribution-ShareAlike 4.0 International License (CC BY-SA 4.0).

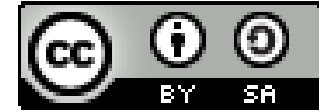

dengan berbagai modalitas bisa memberikan kontribusi positif dalam upaya membantu mengatasi keluhan akibat sindroma piriformis ini. Modalitas yang dimanfaatkan pada penelitian adalah trans electrical nerve stimulation (TENS).[1]. TENS (Transcutaneous Electrical Nerve Stimulation) merupakan alat untuk memberi stimulus kepada aliran darah dan otot syaraf manusia. Gerak manusia dihasilkan oleh kontraksi otot yang 
menghasilkan gaya untuk menggerakan anggota badan.[2] Pada gerak sadar, sinyal perintah dari pusat sistem syaraf ditransmisikan melalui syaraf tulang belakang lalu ke otot untuk menghasilkan gaya.[3][4]. Kerusakan pada sistem syaraf yang diakibatkan penyakit yang menyerang syaraf tulang belakang akan menunggu sinyal perintah mencapai otot. Para ahli sudah banyak mengembangkan bagaimana untuk mempercepat pemulihan anggota gerak tubuh yang mengalami gangguan pergerakan atau kelumpuhan dengan memberikan stimulasi listrik. Diantaranya adalah TENS (Transcutaneous Electrical Nerve Stimulation).[5]. TENS bekerja dengan cara mengirimkan aliran listrik ke otot yang membutuhkan terapi sehingga menyebabkan otot untuk berlatih secara pasif. Penggunaan alat ini mulai banyak digunakan di rumah sakit dan klinik olahraga untuk pengobatan cedera otot dan untuk mengembalikan otot yang mengalami kelumpuhan.[6]. TENS (Transcutaneous Electrical Nerve Stimulation) merupakan suatu cara penggunaan elektroterapeutik untuk merangsang sistem saraf melalui permukaan kulit.[7]. TENS merupakan modalitas yang paling efektif dan telah umum digunakan untuk menghilangkan nyeri pada berbagai kondisi muskuloskeletal.[8]. TENS tidak bersifat adiksi, tidak memicu mual, kantuk serta bebas dilakukan kapan saja sesuai dengan waktu yang diinginkan. TENS mampu menjadi distraksi dari rasa sakit.[9]. TENS mampu mengatasi dismenorea melalui non farmakologis akupuntur. Pada impuls rendah $(2 \mathrm{~Hz})$ endorphin akan diproduksi sebagai penghilang rasa sakit alami.[10][11]. Menurut Permenkes no.54 tahun 2015 bahwa ECT atau TENS termasuk dalam golongan medium risk yang berarti harus dilakukan proses kalibrasi secara berkala oleh Balai Pengujian Fasilitas Kesehatan kelas A, kelas B, atau laboratorium uji dan kalibrasi level 2 (dua) yang terakreditasi. Alat harus terpelihara dengan baik serta memiliki petunjuk pemakaian dan pemeliharaan.[12].

Pada tahun 2002 penelitian yang dilakukan oleh saudara Eriyansyah dan Yuli Munandar Kolewor dari D-III Teknik Elektromedik, Stikes Mandala Waluya, Kendari telah mendesain sebuah alat pengukur arus dan frekuensi akan tetapi dalam penelitian ini masih terdapat kekurangan yaitu pada tampilan masih menggunakan LCD karakter 2x16.[13]. Pengujian alat dilakukan dengan menggunakan oscilloscope untuk mengukur keakuratan keluaran alat, Tujuan dari pengambilan data dan pengujian adalah untuk mengetahui ketepatan dari pembuatan modul yang penulis lakukan atau untuk memastikan apakah masing-masing bagian (komponen) dari rangkaian modul yang dimaksud telah bekerja sesuai dengan fungsinya seperti yang telah direncanakan. Pada penelitian ini terdapat kekurangan yaitu tampilan display masih menggunakan LCD karakter 2x16.[13]. Pada tahun 2014 penelitian yang dilakukan oleh Risalia dari Poltekkes Kemenkes Surabaya telah mendesain sebuah alat kejut terapi akan tetapi dalam penelitian ini bentuk sinyal tidak ditampilkan pada LCD 2x16. [14] [15]. Pada tahun 2014 Itmi Hidayat Kurniawan dan Latiful Hayat dari Fakultas Teknik
Universitas Muhammadiyah Purwokerto membuat sebuah alat ukur arus yang menampilkan sinyal melalui personal komputer. [16]. Tahun 2018 Bima Adhi Nugrohodari Fakultas teknik elektro Universitas Diponegoro Semarang, merancang sebuah alat ukur frekuensi meter yang menampilkan hasil pengukuran dalam bentuk angka pada LCD karakter 2x16.[17]. Tahun 2018 Abdul Adhim dan Endah Rahmawati dari Universitas Negeri Surabaya mendesain sebuah alat dengan judul Rancang Bangun Ampermeter Digital Berbasis Induksi Elektromagnetik. Dalam penelitian ini hasil pengukuran masih ditampilkan pada LCD karakter 2x16.[18][19]

Berdasarkan penelitian diatas, penulis ini ingin mengembangkan dari desain alat yang telah dibuat oleh peneliti sebelumnya. Pengembangan yang ingin dilakukan oleh penulis yaitu untuk penampilan bentuk sinyal dan hasil pengukuran antara frekuensi dan apermeter menjadi satu dalam satu alat. Dalam pengukuran arus penulis menggunakan modul sensor arus tipe ACS 712 dan bentuk sinyal akan ditampilkan pada LCD TFT Nextion 3,2 inch dan untuk hasil pengukuran arus dan frekuensi akan ditampilkan dalam bentuk angka. Dengan menggunakan ATmega 328 sebagai sarana untuk memberikan perintah pada sensor untuk melakukan pembacaan arus.

\section{BAHAN DAN METODE}

\section{A. Experimental Setup}

Penelitian ini menggunakan subyek pembanding berupa alat TENS. Pengambilan data dilakukan secara acak dan dilakukan sebanyak 5 kali.

1) Materials and Tool

Penelitian ini menggunakan sensor arus berjenis ACS712 untuk mendeteksi arus keluaran dari alat TENS yang diletakkan pada input modul penelitian. Komponen lain yang digunakan antara lain rangkaian mikrokontroler Atmega 328 sebagai pemberi perintah pada sensor untuk melakukan pengukuran dan LCD TFT Nextion 3,2 inch untuk mengetahui/menampilkan dari hasil pengukuran yang telah dilakukan oleh modul sensor.

\section{2) Experiment}

Dalam studi penelitian ini peneliti mengukur output sensor arus ketika terjadi perubahan pengukuran dalam perubahan seting pada alat TENS. Pengukuran ini dimaksudkan untuk menguji apakah sensor dapat membaca arus keluaran TENS dengan baik atau sesuai karakteristik pada data sheet sensor dan sesuai dengan keluaran yang ditampilkan pada alat TENS tersebut. Peneliti juga melakukan pengukuran pada output frekuensi untuk melihat berapa besar $\mathrm{Hz}$ yang dikeluarkan oleh TENS menggunakan osiloskop.

\section{B. The Diagram Block}

Pada bagian dari gambar yang diberi garis putus adalah parameter yang penulis buat, yaitu parameter arus dalam satuan $\mathrm{mA}$ dan parameter frekuensi dalam satuan Hz. Sensor 
arus mendeteksi arus keluaran yang dihasilkan oleh TENS kemudian hasil pengukuran akan dikelola oleh mikrokontroler ATmega 328. Data hasil pengelolaan dari mikrokontroler ATmega 328 akan ditampilkan pada LCD TFT Nextion 3,2 inch dalam bentuk angka.

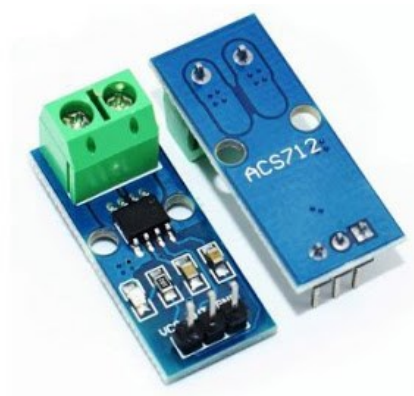

Gambar 1.Sensor Arus ACS 712

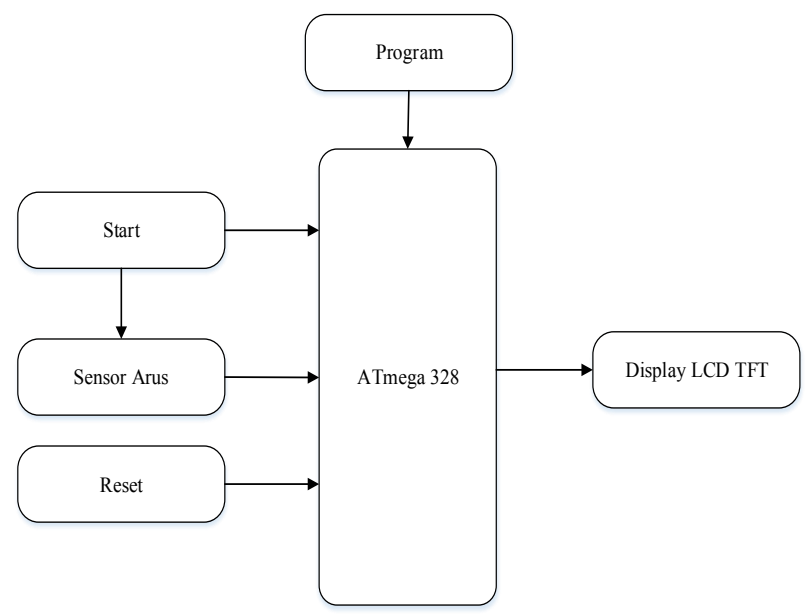

Gambar 2. Diagram Blok

\section{The Flowchart}

Program arduino didasarkan pada flowchart seperti yang ditunjukkan pada gambar 2 dan 3. Setelah inisialisai, sensor akan mulai membaca keluaran dari TENS dan diproses pada ATmega 328, dan setelah hasil pengolahan data selesai maka data hasil pengukuran akan ditampilkan pada LCD TFT Nextion 3,2 inch. Ketika pengukuran selesai maka bentuk sinyal tidak akan muncul kembali.

\section{The Analog Circuit}

Bagian yang paling penting dari penelitian ini adalah modul sensor ACS712. Modul ini digunakan untuk memproses pembacaan besar arus yang telah dikeluarkan oleh alat TENS.

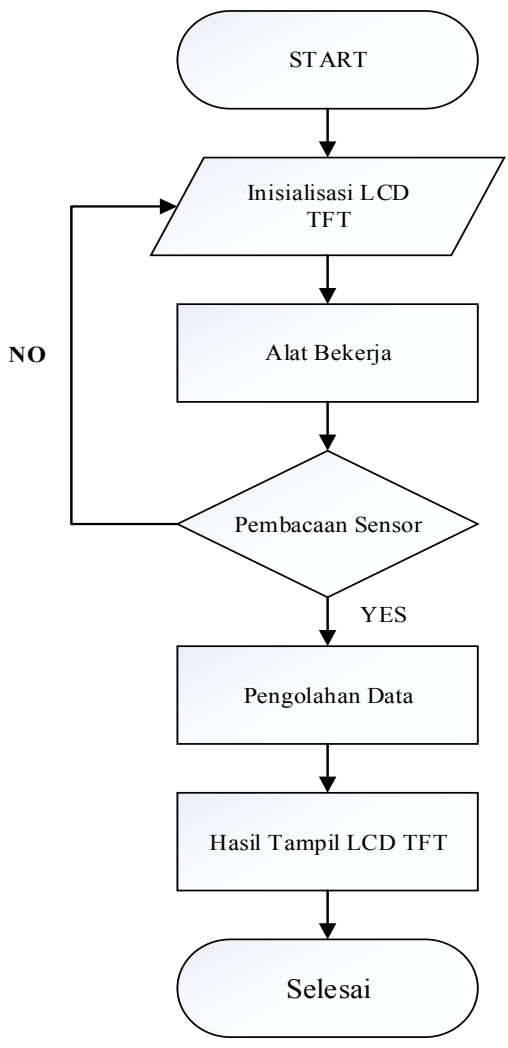

Gambar 3.Flowchart/ diagram alir

\section{1) Microcontroller}

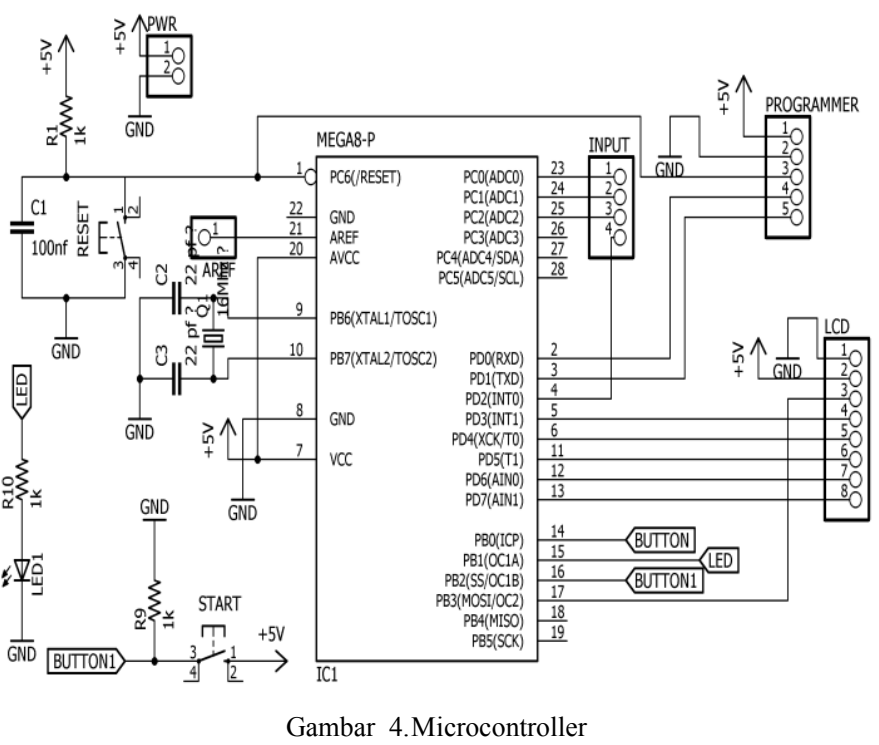

Rangkaian mikrokontroler ditunjukkan dalam gambar... yang digunakan untuk memproses data output dari sensor arus. Dan digunakan untuk transmisi pemrograman .Output dari sensor arus akan dihubungkan ke pin A0 pada ATmega 328.

2) Modul Sensor 
Modul sensor arus yang digunakan dalam penelitian ini adalah AS712. Modul sensor digunakan untuk mentransmisikan data arus keluaran dari alat TENS ke mikrokontroler.

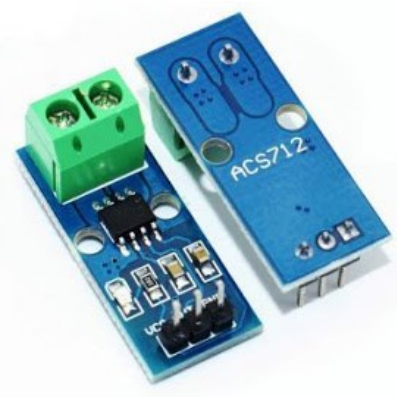

Gambar 5. Modul sensor arus

\section{HASIL}

Penelitian ini belum melakukan pengambilan data pada alat pembanding yang sebenarnya. Penulis disini melakukan pengambilan data pada elektrostimulator yang di desain oleh mahasiswa teknik elektromedik.

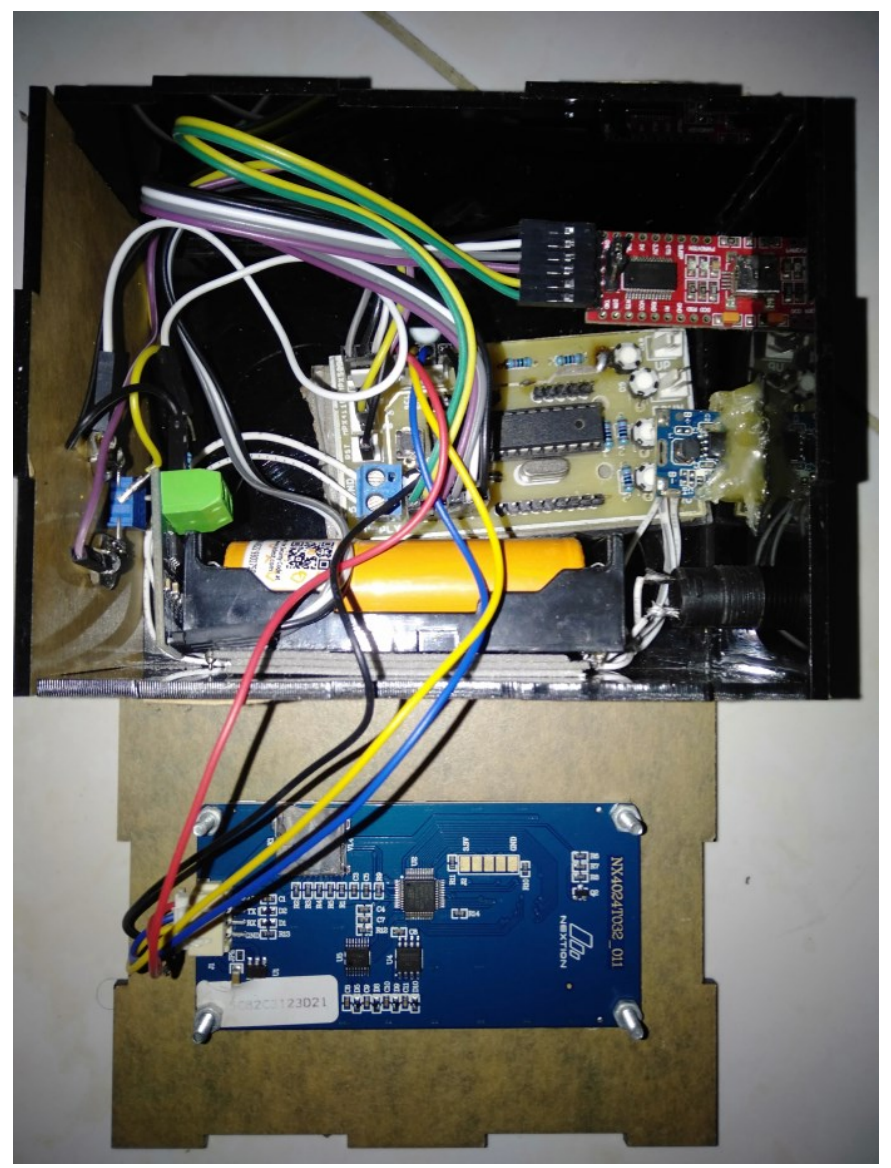

Gambar 6.Circuit Design
1) The Modul Design

Foto dari bagian alat analog ditampilkan pada gambar 4 . Bagian analog adalah modul sensor arus ACS 712. Bagian digital terdiri dari mikrokontroler yang terdiri dari ATmega 328 sebagai pengatur sistem, $16.000 \mathrm{MHz}$ kristal yang berfungsi sebagai jam eksternal untuk fungsi mikrokontroler

2) The Listing Program for Arduino

Daftar program terdiri dari program kalibrasi sensor ditunjukkan dalam daftar 1 program, sebuah program untuk melakukan kalibrasi pada sensor sebelum digunakan. Listing program untuk menampilkan nilai frekuensi ditunjukkan dalam program 2, sebuah program untuk menampilkan nilai arus keluaran ditunjukkan dalam program 3, dan program untuk menampilkan bentuk sinyal pada LCD TFT ditunjukkan dalam program 4 .

Listing program 1. Program kalibrasi sensor

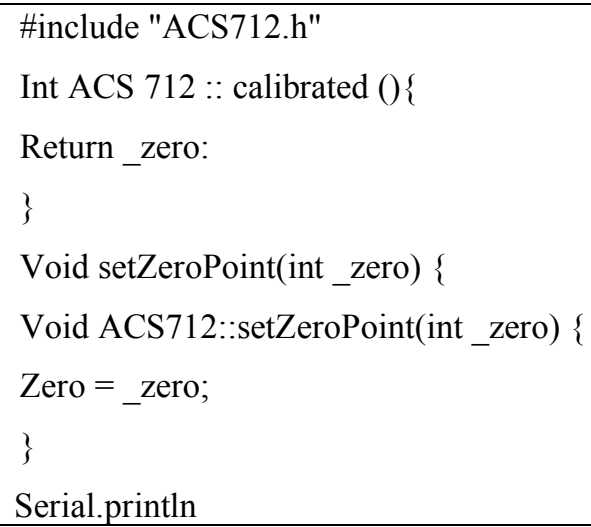

Listing Program 2. Program untuk menampilkan frekuensi

int freq=analogRead(A0)/204;
int freq1= freq*10;
Serial.print("n1.val=");
Serial.print(arus1);
Serial.write(0xff);
Serial.write(0xff);
Serial.write(0xff);

Listing Program 3. Program penampilan nilai arus

\section{void loop()}

\{int arus $=$ analogRead(A0)/204;

int $\operatorname{arus} 1=$ arus $* 10$;

Serial.print("n0.val="); 
Serial.print(arus1);

Serial.write(0xff);

Serial.write(0xff);

Serial.write(0xff);

Listing Program 4. Program penampilan bentuk sinyal pada LCD

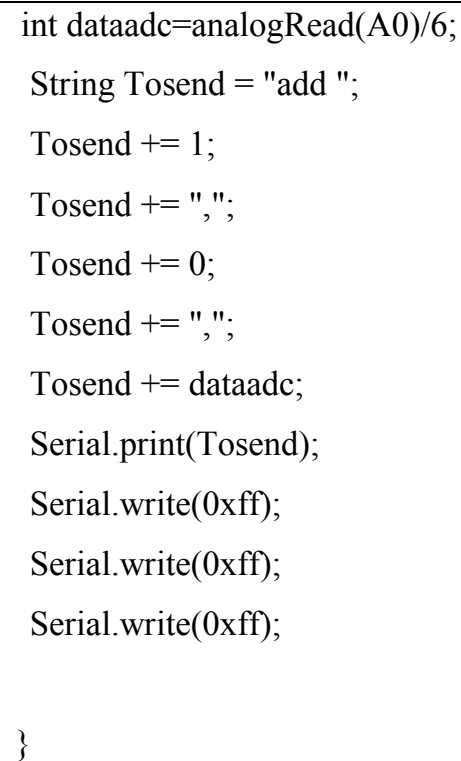

\section{DISKUSI}

Setelah membuat studi literatur dan mempelajari perencanaan pengujian, pengujian dan pengumpulan data atau pengukuran dapat disimpulkan dalam pengukuran arus, semakin besar pengaturan frekuensi pada TENS maka arus yang didapatkan akan semakin besar pula.

Kekurangan dari modul ini adalah tidak menampilkan indikator tegangan yang masuk. Fungsi dari indikator tegangan adalah sebagai pengaman dan modul ini hanya menampilkan satu bentuk sinyal.

Solusi dari modul ini yaitu dengan menambahkan indikator tegangan masuk dan menambahkan bentuk sinyal keluaran menjadi dua bentuk sinyal.

\section{KESIMPULAN}

Berdasarkan hasil diskusi dan tujuan pembuatan modul dapat disimpulkan bahwa modul dapat menampilkan nilai arus, frekuensi dan bentuk sinyal yang telah diprogram arduino dimana hasil yang ditampilkan pada LCD TFT. Setelah melakukan pengukuran pada arus dan frekuensi menunjukkan bahwa sensor arus telah terbukti bekerja dengan baik dan sesuai dengan karakteristik sensor dan pembacaan frekuensi tidak jauh berbeda dengan alat standart. Untuk pembacaan arus penulis menggunakan modul sensor arus jenis ACS 712.

\section{DAFTAR PUSTAKA}

[1] S. Suwarni and F. Nugroho, "Beda Efektivitas Pengaruh Pemberian TENS Dan Stretching Dengan Lllt Dan Stretching Terhadap Penurunan Nyeri Pada Kasus Sindroma Piriformis," Interes. J. Ilmu Kesehat., vol. 8, no. 2, pp. 184-188, 2019, doi: 10.37341/interest.v8i2.174.

[2] L. Li, Y. Z. Chen, H. Zhou, H. Ma, and J. Liu, "The application of hall sensors ACS712 in the protection circuit of controller for humanoid robots," ICCASM 2010 - 2010 Int. Conf. Comput. Appl. Syst. Model. Proc., vol. 12, no. Iccasm, pp. 101-103, 2010, doi: 10.1109/ICCASM.2010.5622149.

[3] Y. Setiawan, "Tens triangle and square wave microcontroller," pp. 1-8, 2016.

[4] G. Rietveld, J. H. N. Van Der Beek, and E. Houtzager, "Accurate DC Current Ratio Measurements for Primary Currents up to 600 A," IEEE Trans. Instrum. Meas., vol. 64, no. 11, pp. 3055-3061, 2015, doi: 10.1109/TIM.2015.2434096.

[5] A. Kuhn, T. Keller, M. Lawrence, and M. Morari, "The influence of electrode size on selectivity and comfort in transcutaneous electrical stimulation of the forearm," IEEE Trans. Neural Syst. Rehabil. Eng., vol. 18, no. 3, pp. 255-262, 2010, doi: 10.1109/TNSRE.2009.2039807.

[6] S. F. Wang, J. P. Lee, and H. L. Hwa, "Effect of transcutaneous electrical nerve stimulation on primary dysmenorrhea," Neuromodulation, vol. 12, no. 4, pp. 302-309, 2009, doi: 10.1111/j.15251403.2009.00226.x.

[7] M. Program, S. Fisioterapi, F. Kedokteran, and U. Udayana, "Pemberian Transcutaneous Electrical Nerve Stimulation ( Tens ) Dapat Meningkatkan Ketajaman," no. August, pp. 1-8, 2013.

[8] A. S. Rizqi, "Transcutaneous Electrical Nerve Stimulation (Tens) Affecting Pain Treshold," Link, vol. 14, no. 2, p. 79, 2018, doi: 10.31983/link.v14i2.3775.

[9] A. Sonwane, C. Y. Patil, and G. Deshmukh, "and Basic Principles for the use of TENS," 2018 2nd Int. Conf. Trends Electron. Informatics, no. Icoei, pp. 285-287, 5193.

[10] S. Pranata, H. Nugroho, and U. Sujianto, "Literature Review Pengaruh Transcutaneous Electrinal Nerve Stimulation ( TENS ) Terhadap Penyembuhan Luka," 
J. keperawatan dan Pemikir. Ilm., vol. 2, no. 1, pp. 112, 2016.

[11] K. Kawahara and S. Suzuki, "Enhancement of spatial awareness on vehicle driving using transcutaneous electrical nerve stimulation," Proc. IEEE Int. Conf. Ind. Technol., vol. 2018-Febru, pp. 1967-1972, 2018, doi: 10.1109/ICIT.2018.8352488.

[12] 2014 Who, “No Title空間像再生型立体映像の 研究 動向,” Nhk技研, vol. 151, pp. 10-17, 2015, doi: 10.1145/3132847.3132886.

[13] E. Yuli and M. Kolewora, "Perancangan Elektrostimulator Berbasis."

[14] D. S. Hj Endang, H. Torib, and Risalia, "Rancang Bangun Elektrostimulator Berbasis Mikrokontroller," J. Ilmiah, Tek. Elektromedik, Politek. Kemenkes Surabaya, Surabaya, 2014.

[15] Y. Ukai, "TFT-LCD manufacturing technology Current status and future prospect," Proc. 14th Int. Work. Phys. Semicond. Devices, IWPSD, pp. 29-34, 2007, doi: 10.1109/IWPSD.2007.4472449.

[16] I. H. Kurniawan and L. Hayat, "Perancangan Dan Implementasi Alat Ukur Tegangan, Arus Dan Frekuensi Listrik Arus Bolak-Balik Satu Fasa Berbasis Personal Computer," Techno, vol. 15, no. 1, pp. 2131, 2014.

[17] B. A. Nugroho, S. Sudjadi, and Y. Christyono, "Rancang Bangun Frekuensi Meter Listrik Berbasis Atmega328," Transient, vol. 7, no. 4, p. 1069, 2019, doi: 10.14710/transient.7.4.1069-1074.

[18] A. Adhiem, E. Rahmawati, and A. Kholiq, "Rancang Bangun Amperemeter Digital Berbasis Metode Induksi Elektromagnetik," Inov. Fis. Indones., vol. 7, no. 3, pp. 36-41, 2018.

[19] B. Mallick and A. K. Patro, "International Journal of Science, Engineering and Technology Research (IJSETR)," Hear. Rate Monit. Syst. Using Finger Tip Through Arduino Process. Softw., vol. 5, no. 1, pp. 84-89, 2016, doi: 10.1107/S0108767392008328. 